\title{
Genetic and clinical patterns of heritable cerebellar ataxias in adults. II Clinical manifestations
}

\author{
K 'KONDO, K HIROTA*, AND T KATAGIRI* \\ From the Department of Neurology, Brain Research Institute, Niigata University, Niigata 951, Japan .
}

SUMMARY Clinical data on 244 probands with spinocerebellar types, 163 with late cortical cerebellar atrophies (LCCA), and 180 with olivopontocerebellar atrophies (OPCA) were analysed. Spinocerebellar cases were divided into three according to their estimated genetic mechanisms: recessive, dominant, or sporadic. Ages of onset were identical in sporadic spinocerebellar types, LCCA, and OPCA, the average being about 50 . They showed highly correlated clinical patterns. In the light of other evidence, these diseases may represent a premature aging process in the central nervous system, probably determined multifactorially. Recessive spinocerebellar cases were very few. There were 127 cases of spinocerebellar types with dominant inheritance, characterised by age of onset around 33 , colourful ocular signs, and spasticity. A large family with this disease was described in which 34 patients were affected through five generations. The computed tomograms showed an almost normal cerebellum and electronystagmograms indicated patterns of vestibulocular impairment. No necropsied case was available among the present material, but in pathological reports of similar cases, major lesions were found in the ventral and the dorsal spinocerebellar tracts, Clarke's columns, and the posterior columns in the spinal cord. This disease, or hereditary spastic ataxia, represented a fairly well-defined entity inherited dominantly among a group of cases with spinocerebellar types, and it was separable from LCCA or OPCA, not only on clinical and genetic grounds, but by a predominantly spinal involvement.

The phenotypes of spinocerebellar degenerations (SCD) are poorly correlated with their genetic patterns. In the first report, ${ }^{1}$ family patterns were analysed in 844 probands with SCD. Only 151 of these represented well-defined genetic entities, including 52 cases of Friedreich's ataxia, and the majority were cases of cerebellar ataxia which were difficult to define clinically and pathologically. Of these cerebellar ataxias, 299 were spinocerebellar types which were inherited in at least three ways, and there were 163 and 180 cases with late cortical cerebellar atrophies (LCCA) and olivopontocerebellar atrophies (OPCA), respectively, which showed weak familial aggregation compatible with no particular single gene inheritance.

These results were based on overall statistical analyses of the family patterns in groups of the cases classified on purely clinical grounds. In the present

\footnotetext{
*Present addresses of Drs Hirota and Katagiri are Department of Neurology, Akita Red Cross Hospital, Akita 010, and Department of Internal Medicine, Yamagata University Hospital, Yamagata 990-23, Japan.

Received for publication 27 June 1980
}

report, clinical patterns were analysed in groups of probands with cerebellar ataxias classified purely on estimated genetic mechanisms, in an attempt to recognise subtle clinical differences, define the disease more precisely, and, if possible, identify separate clinical-genetic entities in these cases.

\section{Materials and methods}

Clinical information on spinocerebellar types, LCCA, and OPCA was analysed in relation to the estimated genetic patterns. When available, results of examinations including computed tomograms (CT) and electronystagmograms (ENG) were used. Collection of probands, procedures and criteria of diagnosis, and tentative classification were described in the first report of this series by Kondo and Sobue. ${ }^{1}$

Genetic analysis in spinocerebellar types suggested that few cases with a young age of onset were recessively inherited. The majority were dominantly inherited, but there were quite a few sporadic cases among the elderly, hardly attributable to mutation or chance isolation in single gene heredities. Therefore, 
clinical patterns in spinocerebellar types will be evaluated classifying the probands into these three groups. Seven cases with age of onset before 20 and with normal and inbred parents were accepted as recessive cases, based on the evidence shown in the first report. In 127 cases with one affected parent, evidence showed them to be dominant cases. There were 110 cases with no affected relative which were pooled to comprise a group in which multifactorial inheritance was suspected. These three groups included 244 cases. The remaining 299 with spinocerebellar types were multiplex cases with normal parents for which no single genetic mechanism could be assumed. Thus they were rejected from the present clinical analyses.

Totals of 163 and 180 cases of LCCA and OPCA, respectively, showed overall family patterns suggesting multifactorial inheritance, ${ }^{1}$ and no further division was made in the two diseases.

All analyses were made for both sexes separately with appropriate age division before overall pooled patterns were evaluated.

CT scans were examined in ten cases with spinocerebellar types, five with LCCA, and 20 with OPCA along with other types of SCD, as well as control cases. Scanning was done $15^{\circ}$ to $20^{\circ}$ obliquely to the orbitomeatal line with an EMI scanner mark I or a Delta scan 507S2 or a General Electric CT/T.

Vestibular and ocular functions were examined by ENG in 16 cases of spinocerebellar types, five of LCCA, and eight of OPCA along with cases of other types of SCD. The methods included records of spontaneous, positional, and gaze nystagmuses, eye tracking test (ETT), and elicitation of optokinetic nystagmus (OKN) as well as caloric nystagmus. Evaluation of rebound nystagmus was made as a part of the gaze nystagmus test, and the failure of fixation suppression (FFS) was also included in the caloric test.

\section{Results}

Clinical statistics are presented first, followed by findings of CT and ENG, and efforts were made to separate recognisable subgroups of cerebellar ataxias. In these results, observations of little genetic interest are kept to a minimum.

\section{CLINICAL PATTERNS}

Age of onset patterns were identical in LCCA and OPCA, as described in the first report. The average ages were $49 \cdot 1$ and 50.0 for male and female cases of LCCA, respectively, while they were $48 \cdot 0$ and $48 \cdot 6$ in OPCA. The ages were distributed with a steep peak and a negative skewness, that is, the curves had longer tails on the younger side. Age of onset ranged from 9 to 64 in spinocerebellar types, the overall averages being $34 \cdot 0$ and $36 \cdot 8$, respectively, for males and females, around which ages the curves had rather wide plateaux. In seven spinocerebellar cases in which recessive transmission was assumed, the age of onset was 10 to 20 . In dominant cases, pooling the two sexes, it was 32.5 on average, and in 110 sporadics the figure was $50 \cdot 2$. Sex difference in the age of onset was negligible in these three spinocerebellar types.

Neurological manifestations other than ataxia are summarised in table 1 for all ages and with the two

TABLE 1 Neurological manifestations in cerebellar ataxias in Japan

\begin{tabular}{|c|c|c|c|c|c|}
\hline & \multicolumn{3}{|c|}{ Spinocerebellar types } & \multirow{2}{*}{$\begin{array}{l}L C C A \\
(n=163)\end{array}$} & \multirow{2}{*}{$\begin{array}{l}O P C A \\
(n=180)\end{array}$} \\
\hline & $\begin{array}{l}\text { Recessive } \\
(n=7)\end{array}$ & $\begin{array}{l}\text { Dominant } \\
(n=127)\end{array}$ & $\begin{array}{l}\text { Sporadic } \\
(n=110)\end{array}$ & & \\
\hline \multirow{2}{*}{$\begin{array}{c}\text { Ocular signs } \\
\text { Nystagmus } \\
\text { Paresis of } \\
\text { ocular } \\
\text { muscles }\end{array}$} & $6 / 7$ & $84 \cdot 1$ & $64 \cdot 5$ & $63 \cdot 5$ & $70 \cdot 6$ \\
\hline & $4 / 6$ & $83 \cdot 0$ & $77 \cdot 5$ & $70 \cdot 4$ & $78 \cdot 7$ \\
\hline \multicolumn{2}{|c|}{ Gaze paralysis $1 / 6$} & $8 \cdot 5$ & $4 \cdot 2$ & $4 \cdot 1$ & 7.9 \\
\hline \multicolumn{6}{|l|}{ Retinitis } \\
\hline \multicolumn{2}{|l|}{ pigmentosa } & & & $2 \cdot 0$ & \\
\hline Cataracts & & $3 \cdot 8$ & $4 \cdot 2$ & $4 \cdot 1$ & $4 \cdot 7$ \\
\hline Other & $1 / 6$ & 23.6 & $14 \cdot 1$ & $18 \cdot 4$ & $11 \cdot 0$ \\
\hline Dysarthria & $7 / 7$ & $96 \cdot 8$ & $93 \cdot 5$ & $80 \cdot 9$ & $94 \cdot 4$ \\
\hline \multicolumn{6}{|l|}{ Atrophy of the } \\
\hline \multicolumn{6}{|l|}{ Paresis of the } \\
\hline lower limbs & $1 / 7$ & $17 \cdot 1$ & $19 \cdot 8$ & $11 \cdot 5$ & $25 \cdot 3$ \\
\hline \multicolumn{6}{|l|}{ Lost or } \\
\hline diminished & $1 / 7$ & $6 \cdot 3$ & $2 \cdot 7$ & $16 \cdot 6$ & $11 \cdot 1$ \\
\hline Normal & $2 / 7$ & $22 \cdot 8$ & $9 \cdot 1$ & $54 \cdot 0$ & $28 \cdot 9$ \\
\hline Exaggerated & $4 / 7$ & $70 \cdot 9$ & $88 \cdot 2$ & 29.4 & $60 \cdot 0$ \\
\hline Babinski reflex & $2 / 7$ & $33 \cdot 3$ & $34 \cdot 0$ & $6 \cdot 3$ & $22 \cdot 0$ \\
\hline \multicolumn{6}{|c|}{ Muscle tone } \\
\hline Diminished & $2 / 7$ & $50 \cdot 0$ & 40.4 & $52 \cdot 7$ & $35 \cdot 2$ \\
\hline Normal & $4 / 7$ & $38 \cdot 1$ & $44 \cdot 7$ & $42 \cdot 6$ & $35 \cdot 2$ \\
\hline Spastic & & $10 \cdot 2$ & $13 \cdot 8$ & 2.0 & $3 \cdot 8$ \\
\hline Rigid & $1 / 7$ & $1 \cdot \overline{7}$ & & $2 \cdot 0$ & $22 \cdot 6$ \\
\hline Other & & & $1 \cdot 1$ & 0.7 & $3 \cdot 1$ \\
\hline \multicolumn{6}{|l|}{ Involuntary } \\
\hline movements & $1 / 7$ & $14 \cdot 5$ & $15 \cdot 2$ & $7 \cdot 5$ & $15 \cdot 3$ \\
\hline Tremors & $3 / 7$ & $31 \cdot 7$ & $25 \cdot 5$ & $25 \cdot 0$ & $38 \cdot 8$ \\
\hline \multicolumn{6}{|l|}{ Sensory } \\
\hline \multicolumn{6}{|l|}{ Mental } \\
\hline disorders & $0 / 7$ & $14 \cdot 5$ & $18 \cdot 3$ & $6 \cdot 8$ & 23.9 \\
\hline \multicolumn{6}{|l|}{ Epileptic } \\
\hline disorders & $0 / 7$ & $3 \cdot 3$ & $1 \cdot 9$ & $1 \cdot 3$ & $1 \cdot 7$ \\
\hline Autonomic & $1 / 7$ & 15.1 & 5.1 & $17 \cdot 3$ & 73.5 \\
\hline
\end{tabular}

The proportion ( $\%$ ) of cases showing a positive sign are represented, excluding those not known, for various neurological signs for four groups of cerebellar ataxias. For the recessive spinocerebellar group of seven cases, the numbers of cases with a positive sign are represented. For each ocular sign, the proportion was calculated from the total of the cases showing one or more of any ocular sign.

Other ocular signs in the dominant spinocerebellar cases included: reduced visual acuity (2), constricted visual field (2), anisocoria (5), loss of the convergence reflex, diplopias (9), strabismus, Parinaud's sign (3), impaired smooth pursuit movements (2), impaired saccadic movements (2), viscosity with saccadic eye movement, blephar ${ }^{\mathrm{r}}$ ospasm, and impairment of eye opening ( 1 each). 
sexes pooled, because there was no appreciable difference by age and sex in any group.

LCCA cases, strictly speaking, should not show neurological abnormalities except cerebellar ataxia. There were about 50 of these cases, but as stated in the first report, LCCA was rather broadly defined in the present material to obtain a sufficient number of probands for age-specific analyses. LCCA and OPCA showed considerable differences which were merely a reflection of the differences in their diagnostic criteria, apart from ocular signs which were not included in the criteria.

This is predictable because, owing to the broadened definition of LCCA, some cases of OPCA with mild or insufficient clinical manifestations of multisystemic involvement are grouped in LCCA. Patterns in table 1 supported the concept that LCCA and OPCA represent a disease spectrum. Western readers will probably be surprised at the high proportions of ocular signs in LCCA and OPCA in Japan.

In spinocerebellar types, sporadic cases showed very similar patterns to OPCA, with differences predictable because of the diagnostic criteria, but in dominant cases, ocular manifestations were frequent and varied. On average, they were severer in this group. Recessive cases were too few to draw conclusions.

\section{COMPUTED TOMOGRAMS}

The details are published by Nagai et $a l^{2}$ with the following major conclusions. (1) In all cases of LCCA, the cerebellar hemispheres were grossly atrophic even in early cases, but there was little evidence of pontine atrophy. (2) In most cases of OPCA, the pons and the brain stem were apparently atrophic even at earlier stages, and some later cases showed varying extents of cerebral atrophy. (3) Sporadic spinocerebellar types showed variable changes from case to case, more or less comparable with OPCA, the patterns being similar in cases from the same family. (4) Dominant cases in the spinocerebellar group had more pontine atrophy but the cerebellum was almost normal.

\section{ELECTRONYSTAGMOGRAMS}

The results, which have been reported separately by Katagiri et $a l^{3}{ }^{3}$ were as follows. (1) Friedreich's ataxia, a disease showing spinal ataxia, presented basically normal patterns except in a few advanced cases with some clinical features of cerebellar involvement. (2) In spinocerebellar types, LCCA, and OPCA, in which there was clinical ataxia of the cerebellar type, ENG also disclosed cerebellar patterns with positive FFS. In other words, caloric nystagmus, which is normally elicited with caloric stimuli to the external auditory meatus, and which is $\stackrel{\mathbb{P}}{=}$ normally suppressed by voluntary fixation of the $\overrightarrow{\vec{F}}$ eyes when the cerebellum is functioning, was not: adequately suppressed in these diseases. (3) In듬 LCCA, ETT was ataxic, OKN was suppressed, and $\overline{\bar{N}}$ horizontal gaze nystagmus was prominent, indicating $\underset{\widetilde{\Phi}}{\overparen{\partial}}$ pure cerebellar patterns, and rebound nystagmus was seen, suggesting hemispheric disorders. (4) In के OPCA, ETT was more or less saccadic as in Parkin- $\overrightarrow{0}$ son's disease, OKN was suppressed particularly in the vertical direction, gaze nystagmus was observed $\vec{\rho}$ in half of the cases, and no rebound nystagmus was? elicited, indicating disturbed vestibulocular functions (5) In spinocerebellar types, the patterns were more $\vec{\infty}$ or less similar to OPCA, as explained later for dominant cases.

\section{CLINICAL-GENETIC CORRELATIONS}

Recessive spinocerebellar cases were few, but were separable on grounds of very young age of onset and $\not$ evidence of recessive heredity.

LCCA and OPCA, as discussed fully in the first吕 report, are known to represent both extremes of a $\vec{c}$ correlated disease spectrum, not only from theo pathological point of view, but by showing identical ${ }^{-}$ family patterns suggesting a multifactorial aetiology. The results in table 1 were compatible with these concepts.

Sporadic spinocerebellar types are probablyő heterogeneous, but the age of onset was identical toळ LCCA and OPCA, and clinical patterns, particularly $\vec{O}$ ocular signs, were remarkably similar to OPCA. As 3 quoted in the first report, most necropsied cases of? Marie's ataxia, to which the present spinocerebellaro types are almost equivalent, showed findings of OPCA. The latter is a multisystemic degenerationo showing extremely variable clinical manifestation, $\frac{0}{3}$ and it may be that most sporadic spinocerebellar cases: are in fact, pathologically speaking, cases of OPCA, in which pyramidal tract signs were prominent but $₹$ other features of typical OPCA were less evident음 clinically.

Dominant spinocerebellar cases are characterised을 not only by a specific mode of transmission, but by onset in middle age and rather colourful ocular manifestations, and are reasonably separable from $\tilde{D}$ the rest of the spinocerebellar cases. Although it was N unclear whether the cases represented one and theog same disease entity, they were tentatively given ao special name and are described separately in the following section.

DOMINANT SPINOCEREBELLAR ATAXIA

WITH SPASTICITY AND

VESTIBULOCULAR IMPAIRMENT

Of a total of 110 cases with this condition, 42 were $\frac{a}{\bar{\alpha}}$ 
personally examined, among which there were 11 cases belonging to one large family. Fig 1 shows the $\mathrm{K}$ family pedigree. The family was ascertained around the city of Niigata among 27 other families which included fewer but similarly affected cases. The family was first observed by Tsujimura ${ }^{4}$ and updated by the present authors. There were 34 patients in five generations and autosomal dominant transmission was definite.

Age of onset was 15 to 51 , the average being 31, with no sex difference. The initial manifestation was instability of gait in all cases. The disease was relentlessly progressive and showed the following clinical patterns in the cases directly examined. Unexamined cases showed similar patterns, according to the medical records we could review.

Ataxia was of cerebellar origin, symmetrical, and more pronounced in the lower than in the upper limbs. Dysarthria was a feature in all 11 cases examined, and mild to moderate ataxic dysphagia was observed in half of the cases. Mild Romberg's sign was observed in six cases,

Ocular manifestations were protean. All cases showed horizontal nystagmus. Fine pendulous upward gaze nystagmus was observed in seven cases, limitation of upward gaze in four, abducens paresis with diplopia in lateral gaze in five, various other diplopias in seven, and difficulty in eye opening in one.
Muscle atrophy was observed in four cases in the distal legs. Muscle tone was spastic in some cases but no case showed other types of hypertonicity except two cases with occasional dystonic movements. Pyramidal tract signs of varying severity were noted in all but three cases and Babinski reflex was observed in five. Sensory impairment characterised some cases. Superficial sensation was reduced in five cases mostly in the distal lower limbs. Vibration senses were reduced in eight, which included these five cases. Mild sphincteric disturbances were seen in four fairly advanced cases.

These patterns represented overall statistics, and advanced cases were likely to manifest more or less all of the possible disorders, whereas earlier cases showed only ataxia and one or more ocular signs.

CT examination was performed in six cases. Evidence of cerebellar atrophy was absent or very mild even in advanced cases. Changes in the cerebrum were also negligible. In all cases, on the other hand, the brainstem, particularly the pons, was grossly atrophic, as seen in fig 2 . Incidentally, one of the cases in this family died of a stroke many years ago. At necropsy pathologists were interested only in the vascular disease, but there was a statement that the cerebellum was not atrophic. No specimen was available.

ENG showed basically identical patterns among

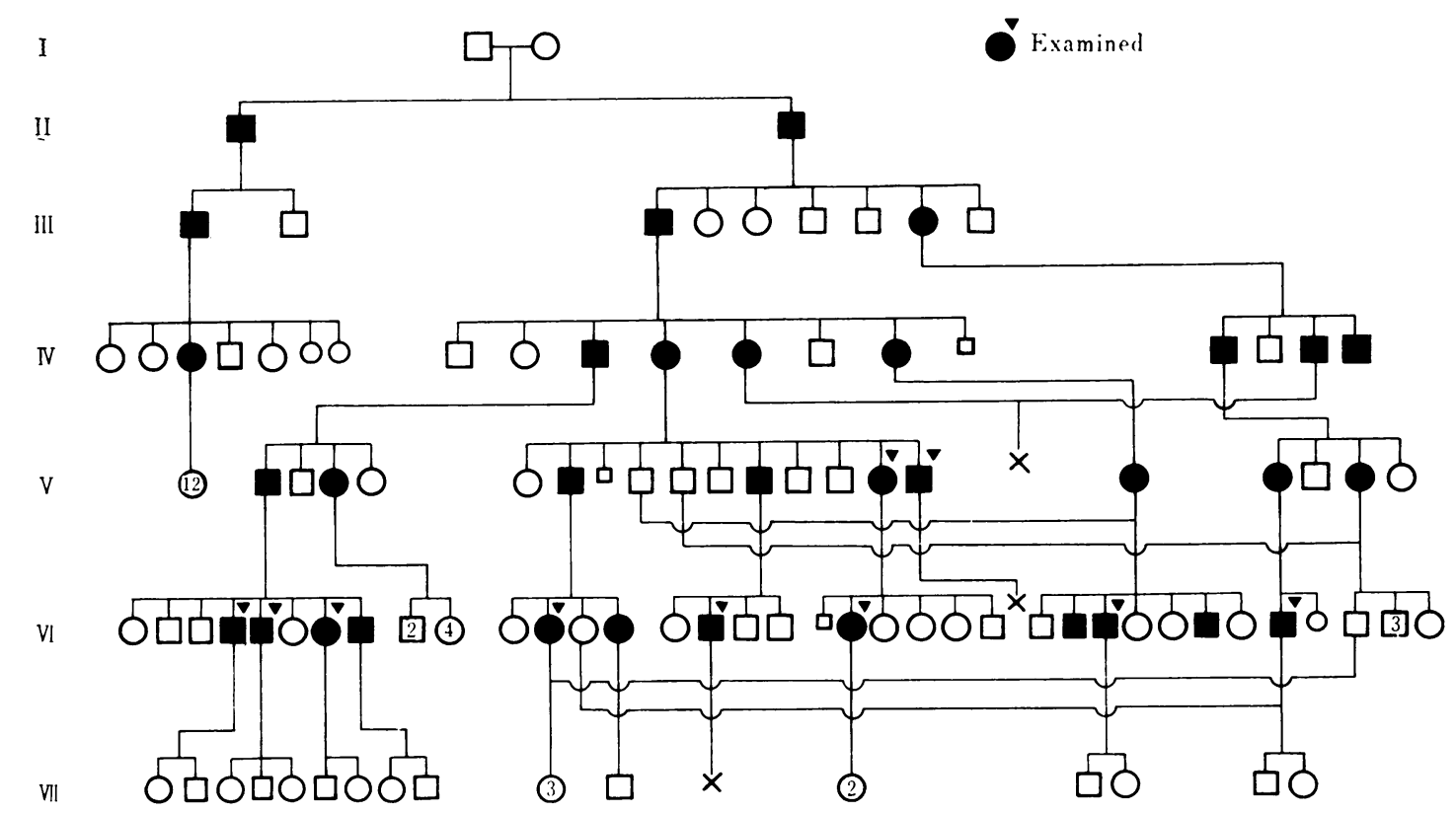

FIG 1 Family K including cases of dominant spinocerebsllar ataxia with spasticity and vestibulocular impairment. A total of 34 members are affected through five generations, including 10 cases directly examined. 


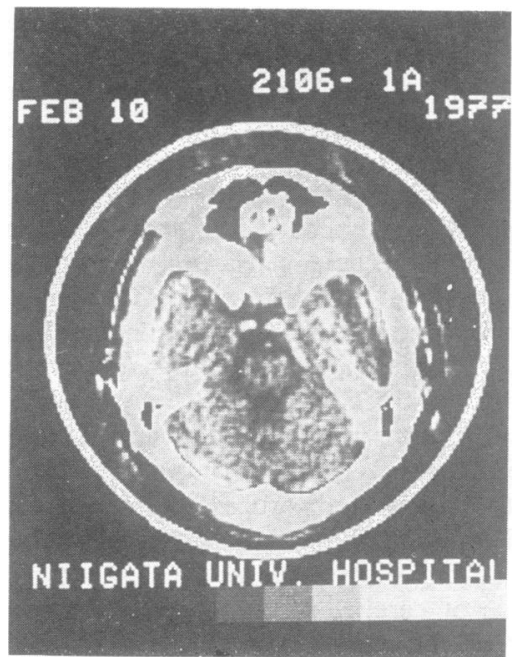

FIG 2 Computed tomogram of a case in family $K$. The picture disclosed severe pontine atrophy but the cerebellum was nearly normal. This male patient, aged 33, the first affected member from the left in generation VI in fig 1, was affected for 16 years and had nystagmus, ocular paresis, increased tendon reflexes, loss of vibration sense, and mild sphincteric disturbance. He was still able to walk with a cane.

six cases with increasing severity in later cases. Spontaneous nystagmus was seen in two cases, gaze nystagmus in all cases in horizontal as well as vertical directions, and rebound nystagmus was observed in three cases. In caloric tests, the response was poor in five and lost in one, and FFS was positive in three. Diminution of OKN was evident particularly in the vertical direction. ETT was slightly saccadic, smooth pursuit movements being impaired. Audiometry was totally normal. These patterns were unique and indicated impaired vestibulocular functions.

\section{Discussion}

Clinical characteristics were compared among five groups of cerebellar ataxias classified by estimated genetic mechanisms.

TWO MAJOR GROUPS OF CEREBELLAR

ATAXIAS IN ADULTS

Excluding a few recessive spinocerebellar cases, abiotrophic cerebellar ataxias appeared to fall into two major groups: one comprising LCCA, OPCA, and sporadic spinocerebellar types, the other comprising dominant spinocerebellar ataxia with spasticity and vestibulocular impairment. The former cases are probably related with systemic 'aging process' of the central nervous system conditioned multifactorially, whereas the latter is a definable $\stackrel{\mathbb{\Phi}}{+}$ monomeric genetic disease entity.

This hypothetical division is based on the estimated genetic mechanisms, as well as clinical patterns, $\frac{C}{0}$ including ages of onset, CT, and ENG, but patho- $\frac{\bar{c}}{\bar{c}}$ logical information was not considered. The latter $\frac{\pi}{\delta}$ was absolutely necessary for adequate division, but $\supseteq$ impossible for technical reasons, as stated in the first $ळ$ report.

LCCA, OPCA, AND SPORADIC

SPINOCEREBELLAR TYPES

These are abiotrophic diseases sharing common features such as (1) age of onset in later life, (2) low. familial aggregation compatible with a multi- $\infty$ factorial aetiology, (3) clinical manifestations inter- is connected with 'mixed' or 'intermediate' cases, and $\sigma$ (4) correlated pathological findings indicating multi- 음 systemic involvement especially of basal ganglia, $\rightarrow$ brainstem nuclei, and the cerebellum and its tracts.

Splitting and lumping have been the two extremesc of attitude in classifying abiotrophic diseases of the $\frac{2}{9}$ central nervous system.

Even though they share these common features, $\stackrel{\oplus}{\oplus}$ LCCA, OPCA, and cases labelled as sporadic. spinocerebellar types in this study may appear as different diseases, which could even be split further for various observed or conjectured reasons. Several reports have been published on this topic. ̊ For instance, five 'subtypes' of OPCA were separated $\stackrel{\mathbb{Q}}{\stackrel{2}{ }}$ by Konigsmark and Weiner. ${ }^{5}$ These publications are $\overrightarrow{\vec{P}}$ not reviewed here, but it appears that efforts to sub- $\frac{3}{3}$ divide the categories are more likely to add further controversy to the nosological debate, rather than to solve the problem, or to propose universally acceptable hypotheses.

CT and ENG may provide new clues for better $\dot{0}$ antemortem diagnoses or classification among and within these interrelated diseases. They are repeatable, $\stackrel{\delta}{\delta}$ non-invasive, and highly effective in evaluating anatomical and functional impairments of the 을 neural structures in the posterior fossa, as shown in the present cases, and in a few works quoted by을 Nagai $e t a l^{2}$ and Katagiri et al. ${ }^{3}$ It is accepted, in the meantime, that homovanillic acid (HVA) in the 9 cerebrospinal fluid reflects activities of the central $N$ dopaminergic neurones. Mizuno and Ariga, ${ }^{6}$ among $\underset{\omega}{N}$ others, investigated HVA in SCD, particularly to distinguish LCCA from OPCA, a disease in which the dopaminergic extrapyramidal system is involved. Values of HVA were lower in OPCA than in other $\stackrel{9}{+}$ types of SCD. Although they are still evolving, CT, ENG, and metabolic information including HVA may in the near future be used to diagnose these $\stackrel{\mathbb{D}}{\stackrel{D}{Q}}$ diseases, which at present are only diagnosed on $\overrightarrow{\mathbb{D}}$ clinical signs and symptoms. The delineation of these 
diseases, however, would still not be clear cut, but it is probable that, viewing preliminary data, these techniques may provide more evidence of their complex interrelations.

Associations with HLA haplotypes is another method of evaluating heterogeneity of various diseases. A few HLA studies of SCD have been published and reviewed by Pedersen et al, ${ }^{7}$ who observed that three of their own families of "cerebellar ataxia' were linked with the HLA system with a combined lod score of $2 \cdot 13$. Negative lod scores were obtained for the remaining family. Cases in this family were characterised by younger ages of onset and higher incidences of dementia and spasticity. HLA studies of SCD are still experimental but here also we see a potential improvement in classification of this perplexing group of diseases.

For those who prefer to amalgamate various seemingly different diseases, on the other hand, even differences such as shown in table 1 may be superficial, and the cases seem to represent one and the same disease continuum. Such a view is eccentric, however, because it cannot explain why, although interrelated, there are different clinical-pathological types. At least in clinical practice, we find little reason to reject time-honoured concepts of these diseases, particularly of LCCA and OPCA.

These considerations are relevant not only to the three diseases discussed, but to other abiotrophic diseases in the elderly: presenile dementias, amyotrophic lateral sclerosis, progressive bulbar paralysis, spinal progressive muscular atrophies, Parkinson's disease, striatonigral degeneration, progressive supranuclear palsy, etc. In these diseases, familial aggregation is not prominent, Mendelian inheritance is not tenable, incidence increases with increasing age, associations with environmental factors are poor, clinical symptoms are similar to the characteristics of aging, and pathological changes, particularly of neurones, are almost identical to those in 'physiological aging'.

Neurones are postmitotic cells, which are highly specialised and which undergo no further cell division. With increasing age of the host, they show a numerical reduction and morphological changes in surviving cells including lipofuscin, senile plaques, amyloid body, Alzheimer's neurofibrillary tangles, etc. Although pathological changes in the aforementioned diseases are marked, systematic, progress more rapidly, and represent serious and irreversible neurological deficits, true differences from 'physiological aging' are quite few. The cause of these diseases is still one of the major enigmas in neurology, but a likely hypothesis is that they are the result of premature and accelerated aging occurring in some systems of the central nervous system in a few genetically predisposed subjects, perhaps influenced by some environmental conditions.

DOMINANT SPINOCEREBELLAR ATAXIA WITH SPASTICITY AND VESTIBULOCULAR IMPAIR MENT

This disease appeared to be separable from other spinocerebellar cases on grounds of heredity, age of onset, and clinical features. No pathological information was available among the present material, however.

The original concept of Marie's ataxia was based on four reports by Brown, ${ }^{8}$ Frazer, ${ }^{9}$ Klippel and Durante, ${ }^{10}$ and Nonne ${ }^{11}$ which appeared to Marie ${ }^{12}$ to represent a disease entity, hérédoataxie cérébélleuse, uniformly characterised by late onset, eye signs, spasticity, and ataxia of cerebellar origin. This 'disease' was thus proposed as it differed from Friedreich's ataxia, the only inherited ataxia known at that time, in which onset is younger, ataxia is of the spinal type, and tendon reflexes are diminished.

Only two cases were necropsied in these four families when the disease was proposed, but later necropsied cases of the families of Frazer and Nonne disclosed conditions resembling cerebellar hypoplasia. In Brown's family, three necropsied cases showed degeneration in the posterior columns, spinocerebellar tracts, and Clarke's columns in all three cases, some atrophy of the anterior horn cells in one case, but little if any degeneration of the brain stem or the cerebellum. Contrary to Marie's presumption, the cases represented ataxia resulting from involvement predominantly in the spinal cord. Four cases necropsied in the family of Klippel and Durante $^{10}$ presented marked changes in the spinal cord, and to a lesser extent in the brain stem and the cerebellum. According to Holmes ${ }^{13}$ the cases bore more resemblance to those of Brown and should be grouped with the spinal ataxias not the cerebellar ataxias, because the only constant lesions were found in the spinal cord.

Consequently, the material on which Marie based his concept of 'hereditary cerebellar ataxia' has proved to be very heterogeneous and to give little support for his thesis. In his book, Greenfield ${ }^{14}$ evaluated pathological findings in hereditary cerebellar ataxia, and found that they fall more or less sharply into either OPCA or LCCA categories, but he realised that the same clinical syndrome can also develop in degenerative disease predominantly affecting the spinal cord, at least in Brown's cases.

Reports of pedigrees involving one or more necropsies of such cases are rare. Available reports are summarised in tables 2 and 3 . The families of Brown as well as of Klippel and Durante have already been mentioned. There are reports of five 
TABLE 2 Neurological manifestations in reported cases of hereditary spastic ataxia

\begin{tabular}{|c|c|c|c|c|c|c|c|}
\hline & $\begin{array}{l}\text { Brown }^{8} \\
\text { (case 6) }\end{array}$ & $\begin{array}{l}\text { Klippel and } \\
\text { Durante } 10 \\
\text { (case III.I) }\end{array}$ & $\begin{array}{l}\text { Matsuyama } \\
\text { et al } 15\end{array}$ & $\begin{array}{l}\text { Boller and } \\
\text { Segarra16 } \\
\text { (case 2) }\end{array}$ & Ishino et al 17 & $\begin{array}{l}\text { Taniguchi and } \\
\text { Konigsmark }^{18}\end{array}$ & Kurachi et al 19 \\
\hline Sex, age at onset/death & Female, $45 / 67$ & Female, 30/57, & $\begin{array}{l}\text { Male, } 29 ? / 39 \text {, } \\
\text { suicide }\end{array}$ & Male, $27 ? / 41$ & Male, $25 / 36$ & Female, 35/54 & Male, $41 / 56$ \\
\hline Initial symptoms & Gait ataxia & Unsteady gait & $\begin{array}{l}\text { Unstable gait, } \\
\text { slow speech }\end{array}$ & Diplopia & $\begin{array}{l}\text { Unstable gait, } \\
\text { diplopia }\end{array}$ & $\begin{array}{l}\text { Unstable gait, } \\
\text { hand } \\
\text { clumsiness }\end{array}$ & $\begin{array}{l}\text { Unstable gait, } \\
\text { diplopia }\end{array}$ \\
\hline Nystagmus & & $\begin{array}{l}\text { Horizontal, } \\
\text { vertical }\end{array}$ & $\begin{array}{l}\text { Horizontal, } \\
\text { vertical }\end{array}$ & + & Horizontal & $\begin{array}{l}\text { Horizontal, } \\
\text { vertical }\end{array}$ & Horizontal \\
\hline Paresis of ocular muscles & & & - & & VI & & III, IV, VI \\
\hline Gaze paralysis & & & Upward & & 一 & & $\begin{array}{l}\text { Upward, } \\
\text { lateral }\end{array}$ \\
\hline Optic nerve atrophy & & & - & & - & & - Dinlonia \\
\hline Other ocular signs & $\begin{array}{l}\text { Weak vision, } \\
\text { ptosis, slow } \\
\text { eye opening }\end{array}$ & & $\begin{array}{l}\text { Anisoconia, } \\
\text { impaired eye } \\
\text { opening, } \\
\text { lagophthalmos }\end{array}$ & Diplopia & $\begin{array}{l}\text { L convergence } \\
\text { paralysis }\end{array}$ & & Diplopia \\
\hline Dysarthria & $\begin{array}{l}\text { Slow but } \\
\text { distinct }\end{array}$ & 一 & + & + & + & + & + \\
\hline Atrophy of the lower limbs & & 一 & + & - & \pm & & - \\
\hline Paresis of the lower limbs & & & - & \pm & 一 & Flexor weak & + \\
\hline $\begin{array}{l}\text { Patellar reflex } \\
\text { Babinski reflex }\end{array}$ & $+t$ & $+t$ & $\begin{array}{l}++ \\
+\end{array}$ & $\begin{array}{l}\overline{+}+ \\
\text { Always } \\
\text { extended }\end{array}$ & $\begin{array}{l}++ \\
+\end{array}$ & $\begin{array}{l}++ \\
+\end{array}$ & $\begin{array}{l}++ \\
+\end{array}$ \\
\hline Muscle tone & & & Spastic & Spastic & Spastic & $\begin{array}{l}\text { Hypotonic, } \\
\text { gait spastic }\end{array}$ & $\begin{array}{l}\text { Normal, later } \\
\text { hypotonic }\end{array}$ \\
\hline Involuntary movements & & & & & - & Tics & - \\
\hline Tremors & & \pm & Eyelid, lip & Tongue & Hand & & 一 \\
\hline Sensory disorders, superficial & - & 二 & - & 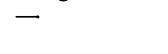 & $\begin{array}{l} \pm \text { in distal } \\
\text { legs }\end{array}$ & + & + distal \\
\hline Sensory disorders, deep & 一 & + & $?$ & - & - & + & $+?$ \\
\hline Romberg's sign & & + & 一 & & \pm & & \pm \\
\hline Mental disorders & - & & - & - & Dementia & - & 二 \\
\hline Autonomic disorders & & 一 & Mild dysuria & $\begin{array}{l}\text { Finally incon- } \\
\text { tinence }\end{array}$ & Finally dysuria & a Spastic bladder & $\begin{array}{l}\text { Finally } \\
\text { pollakisuria }\end{array}$ \\
\hline Others & & & Dysphagia & Choking & $\begin{array}{l}\mathbf{R} \text { nerve deaf- } \\
\text { ness, } \mathbf{L} \\
\text { palatal paresis, } \\
\mathbf{L} \text { caloric low } \\
\text { response }\end{array}$ & $\begin{array}{l}\text { Scoliosis, } \\
\text { Klippel-Feil } \\
\text { anomaly }\end{array}$ & $\begin{array}{l}\text { L tinnitus, } \\
\text { dysacusis, } \\
\text { dysphagia }\end{array}$ \\
\hline
\end{tabular}

One case each is presented for seven families of hereditary spastic ataxia. The cases of Brown and Klippel and Durante are shown first, because they were prototypes of the disease. Other cases are shown in the order of the year of publication. Clinical abnormalities appearing in the final stage only are not presented so that the table is comparable with clinical statistics such as shown in table 1 . Further clinical information of case III. 1 of Klippel and Durante ${ }^{10}$ was supplied by the report of Crouzon and Mathieu (Rev Neurol 1922;38:925).

$(-)$ no or normal, $(+)$ yes or moderate, $( \pm)$ mild, $(++)$ hyperactive patellar reflex, $(?)$ equivocal findings.

more families published, besides several congress abstracts which are not quoted here. The family of Taniguchi and Konigsmark ${ }^{\mathbf{1 8}}$ included Negro cases, and those of Matsuyama et al, ${ }^{15}$ Jshino et $a l,,^{17}$ and Kurachi et al ${ }^{19}$ were Japanese. Thus three major ethnic groups of man, Caucasians, Mongoloids, and Negroids are affected by this disease.

In all families, the pattern of transmission was clearly compatible with autosomal dominant inheritance. Both sexes were equally represented. Ages of onset were in the third to fifth decade. The clinical picture was characterised by colourful eye signs, spasticity, and cerebellar ataxia, basically identical to the patterns for dominant spinocerebellar ataxia with spasticity and vestibulocular impairments which were described in the previous section.

Pathological findings varied among the cases, but major changes were observed in the spinal cord, particularly in the ventral and the dorsal spinocerebellar tracts, Clarke's columns, and the posterior tracts, that is, in the cerebellar afferent systems. Variable, but generally milder, changes were encountered in the nuclei or tracts connected with vestibulocular functions. The cerebellum was mildly affected if any lesion was found.

These patterns totally differ from those in LCCA and OPCA. In LCCA, major changes occur in the cerebellar cortex, greatest in the superior parts of the vermis in typical cases, with a severe loss of Purkinje $N$ cells and some loss of the granule cells. Cerebelloolivary fibres are often affected. That is, the key change is observed in the cerebellar efferent system. In OPCA, severe changes are usually seen in the nuclei in the pons and in the middle cerebellar peduncles which contain the pontocerebellar fibres and other cerebellipetal tracts from the brainstem, but the lesions are not limited to these systems and involve various structures in the central nervous system in a variety of distributions and severity, representing a widespread multisystemic involvement. 
TABLE 3 Pathological findings in reported cases of hereditary spastic ataxia

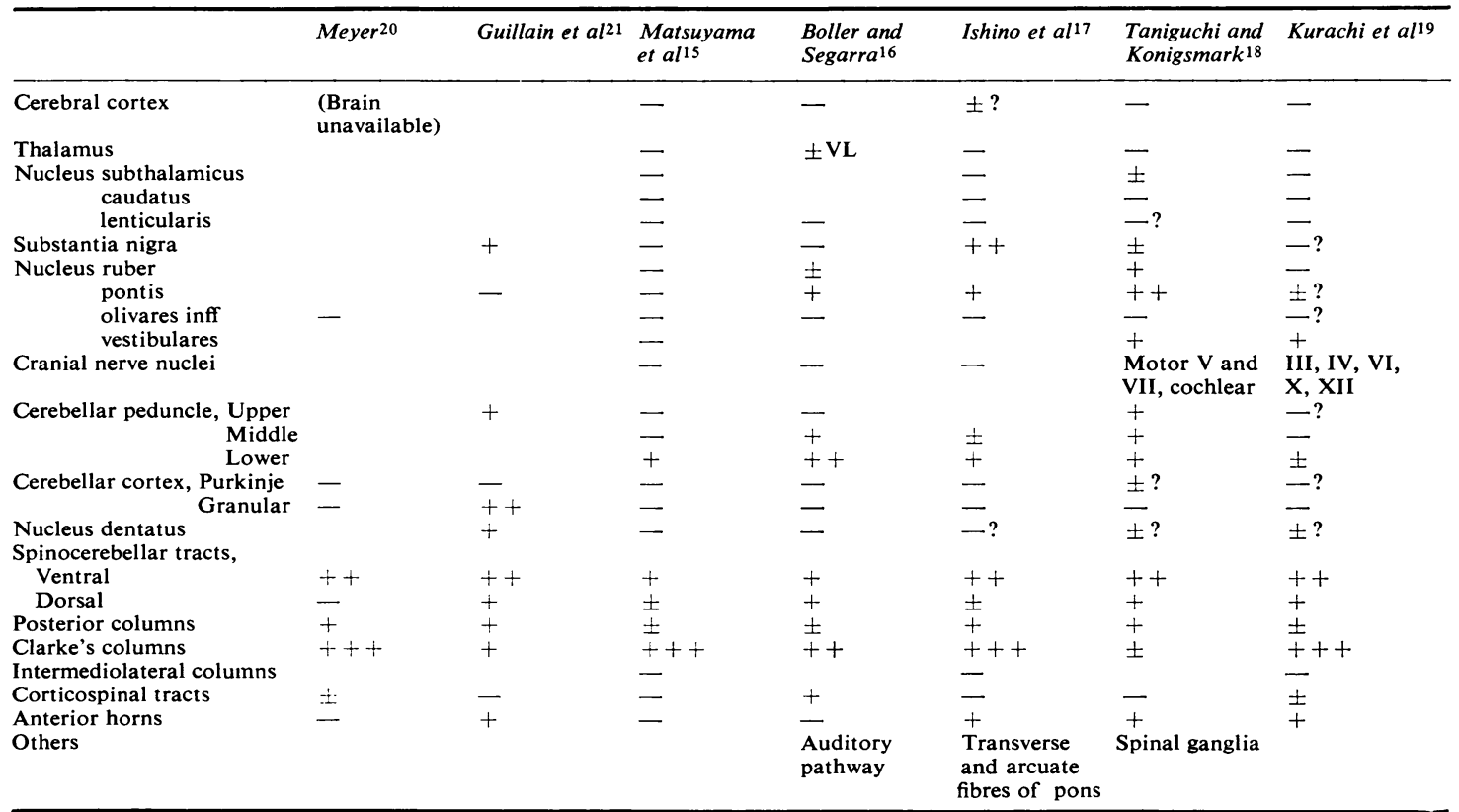

Pathological findings in the cases shown in table 2 are summarised. The information for the cases of Brown ${ }^{8}$ and $\mathrm{Klippel}$ and $\mathrm{Durante}^{10}$ were presented by Meyer ${ }^{20}$ and Guillain et al, ${ }^{21}$ respectively.

$(-)$ no or normal, $(+)$ yes, moderate or unspecified grade, $( \pm)$ mild or some, $(++)$ marked or severe, $(+++)$ almost no cells, $($ ?) equivocal findings.

In conclusion, clinical, pathological, and genetic evidence indicated that this disease is an entity separable from the LCCA/OPCA spectrum and sporadic spinocerebellar cases occurring at elderly ages. Necropsy cases are rare, apparently because of its benign nature, but the disease may constitute a considerable proportion of spinocerebellar cases in middle age.

Nomenclature is confused as shown by the titles of the reports quoted in table 2 . Using several clinical and pathological characteristics, Taniguchi and Konigsmark ${ }^{18}$ suggested that the disease might be named 'dominant spinopontine atrophy'. The present authors tentatively refer to this disease, on clinical and genetic grounds, as 'dominant spinocerebellar ataxia with spasticity and vestibulocular impairment', to separate it from other cerebellar ataxias. We do not, however, propose this name for this clinicopathological entity, but suggest calling it simply 'hereditary spastic ataxia' after Greenfield who, from the pathological point of view, separated this condition from the LCCA/OPCA spectrum by grouping it in his 'spinal forms'.

The best account of this condition is probably a review by Eadie $^{22}$ who stated that it bridges the gap between two of the better established entities,
Friedreich's ataxia and Menzel's type of OPCA. After a comprehensive description of Brown's family, ${ }^{8}$ he included the cases of Klippel and Durante, ${ }^{10}$ Boller and Segarra, ${ }^{16}$ Taniguchi and Konigsmark, ${ }^{18}$ and Ishino et al ${ }^{17}$ in the same disease, but whether such a broadened view of hereditary spastic ataxia will prove valid is a matter for future judgement.

Although some differences were observed from case to case, similarities were far greater among our cases of dominant spinocerebellar ataxia with spasticity and vestibulocular impairment. The authors found this disease essentially identical to the concept of hereditary spastic ataxia, as broadened by Eadie with the cases of Brown as paradigms, and found no reason to subdivide it into smaller groups. It is advisable to pool the cases into one disease until evidence of its heterogeneity is discovered.

\section{PROBLEMS UNSOLVED}

The present study was able to answer most of the problems which emerged from the first report. However, various types of SCD have been defined pathologically, and even though this typing is used clinically, antemortem diagnoses require pathological verification. In the first report and this one, 
family patterns of clinically defined diseases have been analysed. This makes it absolutely necessary to analyse pertinent aspects of necropsied cases, to evaluate whether conclusions in these studies are compatible with the patterns in the verified cases.

This analysis will be made in the third report of the present series.

This study was supported by a grant from the Intractable Diseases Division, Ministry for Health and Welfare, Japan. Cordial thanks are due to Miss Ryuko Sato for her excellent assistance.

\section{References}

1 Kondo K, Sobue I. Genetic and clinical patterns of heritable cerebellar ataxias in adults. I Genetic analyses. J Med Genet 1980;17:416-23.

2 Nagai H, Hirota K, Katagiri T, Kurita I, Takeda N. Computed tomography of spinocerebellar degenerations. CT Studies (Tokyo) 1979;1:529-38.

${ }^{3}$ Katagiri T, Hirota K, Kondo K. Genetics of spinocerebellar degenerations, dominant spinocerebellar ataxia with spasticity and impairments of vestibulocular functions. Adv Neurol Sci 1979;23:1176-86.

4 Tsujimura F. Genetic and clinical studies of hereditary ataxias. Adv Neurol Sci 1959;3:587-601.

5 Konigsmark BW, Weiner LP. The olivopontocerebellar atrophies, a review. Medicine 1970;49:227-41.

- Mizuno Y, Ariga T. Cerebrospinal fluid homovanillic acid in paralysis agitans and spinocerebellar degeneration. Clin Neurol (Tokyo) 1979;19:367-71.

7 Pedersen L, Platz P. Ryder LP, Lamm LU, Dissing J. A linkage study of hereditary ataxias and related disorders, evidence of heterogeneity of dominant cerebellar ataxia. Hum Genet (in press).

8 Brown S. On hereditary ataxy, with a series of twenty-one cases. Brain 1892;15:250-82.

9 Frazer D. Defect of the cerebellum occurring in a brother and sister. Glasgow Med J 1880;13:199-210.
10 Klippel M, Durante G. Contribution a l'étude des affections nérvéuses familiales et hereditaires. $R e v$ Med $1892 ; 12: 745-85$

11 Nonne M. Ueber eine eigentümliche familiäre Erkrankungsform des Zentralnervensystems. Arch Psychiatr Nervenkr 1905;22:283-316.

12 Marie P. Sur l'hérédo-ataxie cérébelleuse. Sem Med $1893 ; 13: 444-7$.

13 Holmes G. An attempt to classify cerebellar disease, with a note on Marie's hereditary cerebellar ataxia. Brain 1907;30:545-67.

14 Greenfield JG. The spinocerebellar degenerations. Springfield, Illinois: Thomas, 1954

15 Matsuyama H, Shimizu K, Katayama T, Goto Y, Fujita R. A case report of hereditary ataxia. Clin Neurol (Tokyo) $1961 ; 1: 146-50$.

16 Boller F, Segarra JM. Spino-pontine degeneration. Eur Neurol 1969;2:356-73.

17 Ishino $\mathbf{H}$, Sato $M$, Terao A, Hayahara T, Otsuki S, Hoaki T. Hereditary spastic ataxia, report of a family through four generations. Folia Psychiatr Neurol Jpn $1971 ; 25: 269-81$.

18 Taniguchi R, Konigsmark BW. Dominant spinopontine atrophy, report of a family through three generations. Brain 1971;94:349-58.

19 Kurachi M, Shibata T, Koyama Y, Isaki K, Yamaguchi N. Marie's ataxia with nuclear external ophthalmoplegia and muscle atrophy of lower extremities, report of an autopsy case and its family. Folia Psychiatr Neurol Jpn 1977;79:1-25.

20 Meyer A. The morbid anatomy of a case of hereditary ataxy. Brain 1897;20:276-89.

21 Guillain G, Bertrand I, Godet-Guillain J. Etude anatomique d'un cas d'hérédo-ataxie cérébelleuse. Rev Neurol (Paris) $1941 ; 73: 609-61$.

22 Eadie MJ. Hereditary spastic ataxia. In: Vinken PJ, Bruyn GW, eds. Handbook of clinical neurology. vol 21. System disorders and atrophies. part 1. Amsterdam: North-Holland, 1975:365-75.

Requests for reprints to Dr K Kondo, Department of Neurology, Brain Research Institute, Niigata University, Asahimachi 1, Niigata 951, Japan. 